\title{
PROGRAMA DE PROMOÇÃO À PERMANÊNCIA: PERFIL DOS DISCENTES DO INSTITUTO FEDERAL DE CIÊNCIA E TECNOLOGIA DE BRASÍLIA
}

\author{
E. M. C. REIS*, A. O. GONÇALVES** \\ *Instituto Federal de Educação, Ciência e Tecnologia de Brasília \\ **Programa de Pós Graduação em Ciências Contábeis - Universidade de Brasília \\ andreagon@unb.br
}

Submetido 22/02/2016 - Aceito 01/08/2018

DOI: $10.15628 /$ holos.2018.4044

\section{RESUMO}

Este artigo apresenta resultados preliminares de estudo que analisa o perfil socioeconômico dos discentes contemplados pelo Programa de Promoção à Permanência, do Instituto Federal de Educação, Ciência e Tecnologia de Brasília (IFB), no exercício de 2014. O Programa de Promoção à Permanência integra a Política de Assistência Estudantil regulamentada em 2014, tendo como base o Programa Nacional de Assistência Estudantil (PNAES) do Governo Federal. Utilizou-se como metodologia o estudo de caso exploratório descritivo de natureza qualitativa. Os dados foram coletados por meio de dados secundários da base existente na Coordenação de Assistência Estudantil e Inclusão Social e foram analisados por meio de estatística descritiva. Como prévia, os resultados apontaram que $64,53 \%$ dos discentes contemplados pelo programa estavam desempregados. Levando-se em consideração que a maioria dos discentes cursou o nível médio e está na faixa etária superior a 18 anos de idade, denota-se que há um percentual elevado de discentes fora do mercado de trabalho e em busca de capacitação, o que ratifica serem beneficiados por este Programa, que auxilia na permanência no curso. Tendo em vista o perfil dos contemplados pelo programa, infere-se que o benefício ofertado equivale a um auxílio importante em detrimento das condições socioeconômicas dos discentes, o que, de fato, auxilia em sua permanência no ensino superior e na conclusão no curso.

PALAVRAS-CHAVE: Programa; Educação profissional; Política pública; Assistência estudantil

\section{RESIDENCE PROMOTION PROGRAM: PROFILE OF STUDENTS INSTITUTO FEDERAL DE CIÊNCIA E TECNOLOGIA DE BRASILIA}

\begin{abstract}
This paper presents preliminary results of a study that analyses the socioeconomic profile of the students covered by the Permanent Promotion Program of Instituto Federal de Brasília in the year of 2014. That Program is part of the Student Assistance Politic regulated in 2014 on the basis of the Student Assistance National Program of the Federal Government. The methodology was an exploratory and descriptive case study. The data was collected from a secondary data found on Coordination of Student Assistance and Social Inclusion and this data was analysed by descriptive statistic. The first results point out that $64,53 \%$ of the
\end{abstract}

students covered by the program were unemployed. Taking into account that they mostly studied high school and they are in the age group higher than 18 years old we observe that exists an increase of the number of students out of the job market and searching for capacitation. So, that information confirms the thesis that the students that are covered by the Program remains in the course. Thus, as the students have difficult socioeconomic conditions the assistance that they received is a condition of their permanence and course conclusion.

KEYWORDS: Program; Professional education; Public policy; Student assistance. 


\section{INTRODUÇÃO}

O Programa Nacional de Assistência Estudantil (PNAES) foi instituído, pelo Ministério da Educação (MEC), por meio da Portaria no 39, de 12 de dezembro de 2007, sendo delimitado pelos tipos de ações que são desenvolvidas dentro das instituições de ensino com o intuito de combater desigualdades sociais. O mencionado Programa tornou-se uma política de Estado com a publicação do Decreto no 7.234, de 19 de julho de 2010. Com o propósito de assegurar a permanência dos estudantes e a conclusão do curso por eles, tendo como meta reduzir as taxas de evasão e, naturalmente, promover a inclusão social por meio da educação, o mencionado decreto regularizou as práticas individualizadas existentes nas instituições de ensino superior e de ensino técnico.

Merece destaque o artigo 40 do Decreto, que incluiu, no PNAES, os institutos federais de educação, ciência e tecnologia, que compõem a Rede Federal de Educação Profissional, Científica e Tecnológica, considerando-se suas especificidades e as áreas estratégicas de ensino, visando atender ao seu corpo discente. Dessa forma, a assistência estudantil, no âmbito dos institutos federais, inclui todos os seus alunos, tanto os do ensino técnico, como os do ensino superior.

Em decorrência do PNAES, o Instituto Federal de Brasília (doravante IFB) buscou regulamentar sua política própria e, na atualidade, encontra-se vigente a Política de Assistência Estudantil (PAE), regulamentada pela Resolução no 14/2014/CS-IFB.

$\mathrm{O}$ artigo 18 da PAE instituiu três grupos de programas para serem desenvolvidos no âmbito do IFB: o universal, o de promoção à permanência e o de incentivo ao desenvolvimento acadêmico. Considere-se que o IFB está contemplado, para a implementação do PNAES, como se observa no Decreto no 7.234/2010, o que proporcionou à instituição construir internamente sua PAE, com o intuito de garantir o acesso e, por conseguinte, a permanência do discente no curso até a conclusão desse.

O PNAES, pela sua amplitude e significância, desperta o interesse em como o tema tem sido trabalhado no âmbito das Instituições Federais de Ensino Superior (IFES). No entanto, como são muitas as IFES, para melhor averiguar os efeitos da política pública estabelecida, torna-se necessário ao desenvolvimento deste estudo limitar a discussão ao IFB, o qual trabalha com a educação nos níveis técnico e superior, que serão tratados nesta investigação.

Tendo em vista a execução do PAE no âmbito do IFB, surge a seguinte questão de pesquisa: qual o perfil dos discentes contemplados no Programa de Promoção à Permanência do Instituto Federal de Educação, de Ciência e Tecnologia de Brasília? Portanto, o objetivo deste artigo é descrever o perfil dos discentes contemplados no Programa de Promoção à Permanência. Para a concretização desse objetivo, será necessário compreender o PNAES, descrever a Política de Assistência Estudantil (PAE) em execução no IFB e descrever o perfil socioeconômico dos discentes contemplados pelo Programa de Promoção à Permanência.

Dessa forma, este artigo apresenta resultados preliminares de estudo que analisa o perfil socioeconômico dos discentes contemplados pelo Programa de Promoção à Permanência do IFB, no exercício de 2014. 
O artigo está organizado em cinco seções, incluindo-se esta introdução. Na seção 2, apresenta-se uma breve revisão bibliográfica que aborda a origem da política no âmbito do IFB. A terceira seção aborda o percurso metodológico e a forma como os dados foram coletados e analisados. A quarta seção expõe os resultados e as discussões. Por fim, as conclusões refletem o perfil dos discentes.

\section{REVISÃO BIBLIOGRÁFICA}

Esta seção apresenta um ensaio acerca da vulnerabilidade socioeconômica, com abordagem do Programa Nacional de Assistência Estudantil (PNAES) e da Política de Assistência Estudantil (PAE) vigente no IFB.

\subsection{Política Nacional de Assistência Estudantil - PNAES}

Araújo e Bezerra (2007) descrevem que a trajetória histórica da assistência estudantil teve sua origem com os programas de alimentação e moradia universitária implantados na década de 30 do século passado, porém o seu desenvolvimento e a sua ampliação como uma política só foram efetivados nos anos 1970, com a criação do Departamento de Assistência Estudantil - DAE.

Nesse contexto, a Lei no 4.024/1961, que trata das Diretrizes e Bases da Educação, foi a primeira lei a tratar especificamente da educação, em nível nacional, após treze anos de debates de diferentes correntes educacionais.

A Lei no 4.024, de 20 de dezembro de 1961, criada com base em dispositivo constitucional, que regula a competência da União, entendeu que a função de legislar sobre diretrizes e bases da educação nacional deveria constar de um texto legal único. Assim, o Poder Executivo, em 1948, encaminhou ao Congresso projeto de Lei que originou muitos debates entre diferentes correntes educacionais, resultando na Lei de Diretrizes e Bases da Educação Nacional de no 4.024/1961, a primeira a tratar especificamente da educação nacional, após 15 anos da promulgação da Constituição de 1946 (REIS, 2007, p. 2).

Após a promulgação da Constituição de 1967, foi publicada a Lei no 5.540/1968, que trata da Lei de Diretrizes e Bases da Educação Superior. Contudo, houve a necessidade de se fazer alterações na Lei no 4.024/1961, em razão de solicitações do Congresso Nacional, a partir do que foi publicada a Lei no 5.692, de 11 de agosto de 1971, que trouxe a lume a segunda Lei de Diretrizes e Bases da Educação - LDB.

Reis (2007, p. 3), ao tratar da Lei no 5.692/1971, evidencia que as alterações propostas por essa lei têm início em maio de 1971, na Faculdade de Educação (FE) da Universidade de Brasília (UnB), onde numeroso grupo de representantes de diferentes instâncias educacionais de todo o Brasil é convidado, pelo então Ministro Jarbas Passarinho, do MEC, a participar do "Curso de Especialização sobre o ensino de 1ㅇ e 2 o graus", cuja finalidade foi a de elaborar o anteprojeto da lei de reforma do ensino, que culminou na elaboração e promulgação da Lei 5.692/1971, também conhecida como "Reforma Passarinho".

De acordo com Araújo e Bezerra (2007), a década de 80 do século passado, no Brasil, foi marcada pela consolidação do poder público, com destaque para projetos de reestruturação da política educacional, tendo-se como exemplo a Comissão Nacional da Reformulação da Educação Superior Brasileira, constituída em 1985, que propunha uma Nova Política para a Educação Superior. 
O Fórum Nacional de Pró-Reitores de Assuntos Comunitários (FONAPRACE) foi criado em 1987, assim como a Associação Nacional dos Dirigentes das Instituições Federais de Ensino Superior (ANDIFES), os quais impulsionaram as discussões sobre as questões educacionais, com ênfase nos quesitos referentes à assistência estudantil. A esse respeito, Vasconcelos (2010, p. 402) assim se posiciona:

\begin{abstract}
Esses dois segmentos educacionais defendiam a integração regional e nacional das instituições de ensino superior, com objetivo de garantir a igualdade de oportunidades aos estudantes das Instituições Federais de Ensino Superior (IFES) na perspectiva do direito social, além de proporcionar aos alunos as condições básicas para sua permanência e conclusão do curso, contribuindo e prevenindo a erradicação, a retenção e a evasão escolar decorrentes das dificuldades socioeconômicas dos alunos de baixa condição socioeconômica.
\end{abstract}

Os anos de 1987 e 1988, sobretudo este, representam um divisor de águas para a educação nacional. Em 10 de fevereiro de 1987, após pressões políticas e dos diversos movimentos populares, foi instalada, no Congresso Nacional, a Assembleia Nacional Constituinte, cujos trabalhos, encerrados em 22 de setembro de 1988, após a votação e aprovação do texto final da nova Constituição brasileira, deram origem à promulgação da Constituição Federal de 1988, apelidada de Constituição Cidadã, que representou um marco histórico nas questões referentes à inclusão dos direitos políticos e sociais dos brasileiros.

De acordo com Vasconcelos (2010, p. 402), “A trajetória histórica da Assistência Estudantil no Brasil está conectada com a trajetória da política de assistência social, pois ambas despontam a partir dos movimentos sociais que lutaram pelo fim do regime militar e da promulgação de uma nova Constituição Federal".

A Constituição de 1988, precisamente em seu artigo 60, expõe que a educação consiste em um dos direitos sociais e, mais à frente, na seção I do Capítulo III, define que a educação é direito de todos e dever do Estado e da família. Dessa forma, coube à União, com base no art. 22, legislar privativamente sobre as diretrizes e bases da educação nacional.

Em vista da conjuntura da Constituição de 1988, foi publicada a Lei no 9.394/1996, que é a mais recente Lei de Diretrizes e Bases da Educação Nacional, vigente até os dias atuais, embora, nesse percurso, tenha havido alterações de seu texto. Esta LDB, em seu artigo 3ㅇ, ampara a assistência estudantil, ao prever que "o ensino será ministrado com base nos seguintes princípios: I - igualdade de condições para o acesso e a permanência na escola".

Com o intuito de conhecer qual era o perfil socioeconômico e cultural dos discentes no ensino superior, o FONAPRACE, no interregno compreendido entre 1995 e 1997, realizou uma pesquisa para concretizar esse levantamento.

O perfil de aluno traçado foi o seguinte: a maioria era do sexo feminino, com idade mediana de 22 anos, solteiros, um universo de $58 \%$ não trabalhava, enquanto o restante (42\%) possuía uma atividade remunerada; um número significativo de pais desses alunos já possuía instrução universitária; outro dado apontado é que $12,17 \%$ dos universitários possuíam filhos. A pesquisa apontou, ainda, que $2,40 \%$ residiam nas moradias estudantis das IFES, os restaurantes universitários garantiam a alimentação diária de $19,10 \%$ e o transporte coletivo $(60,6 \%)$ era o meio de locomoção até as aulas mais utilizado (SILVEIRA, 2012, p. $60)$.

Com os resultados dessa pesquisa, o FONAPRACE conseguiu averiguar que havia estudantes de várias classes sociais cursando o nível superior, e não apenas estudantes oriundos de famílias ricas. 
Ao comentar o assunto, Silveira (2012, p. 62), sugere que, "fossem cruzados os dados dessa pesquisa com outra realizada sobre evasão e retenção no ensino superior, com o objetivo de correlacionar a assistência estudantil e a produtividade acadêmica".

No exercício de 2001, com base na pesquisa do perfil dos discentes, o FONAPRACE elaborou uma proposta de Plano Nacional de Assistência aos Estudantes de Graduação das Instituições Públicas de Ensino Superior, cujo objetivo era listar diretrizes para a definição de programas de assistência ao estudante, com a finalidade de reduzir as desigualdades socioeconômicas.

No período compreendido entre 2003 e 2004, o FONAPRACE iniciou nova pesquisa de perfil de discentes, com o intuito de atualização de dados, e se deparou com uma realidade em que $43 \%$ do alunado se encontravam em uma faixa de renda preocupante, pois as famílias pareciam não possuir condições de manter o jovem nos estudos em razão dos custos: "Nas pesquisas realizadas, constatou-se que $43 \%$ dos estudantes pertenciam às classes $C, D$ e $E$, categorias que englobam alunos provenientes de famílias cuja renda familiar é baixa, às vezes, não suficiente para manter um membro na universidade, com todos os gastos que isso gera" (SILVEIRA, 2012, p. 67).

Como forma de garantir o acesso e a permanência do aluno nas instituições de ensino, o Governo Federal criou, em 12 de dezembro de 2007, o Programa Nacional de Assistência Estudantil (PNAES), com a finalidade de garantir apoio aos estudantes que tinham interesse de ingressar no ensino superior e que não possuíam condição financeira necessária para a permanência nas instituições e, consequentemente, possibilidade para concluir o curso.

O PNAES foi implantado como uma das ações oriundas do Plano de Desenvolvimento da Educação (PDE), com objetivo de atender aos estudantes matriculados em cursos de graduação das Instituições Federais de Ensino Superior (IFES), visando à permanência e à conclusão dos cursos pelos alunos com insuficiência de condições financeiras. Três anos depois de sua criação, o PNAES foi transformado em uma política de Estado, por meio do Decreto no 7.234, de 19 julho de 2010, concebido para ser executado pelo MEC, com vistas a ampliar as condições de permanência dos jovens na educação superior pública federal, tendo estabelecido diretrizes para a execução das ações referentes à assistência estudantil aos alunos que necessitavam de atendimento prioritário.

No PNAES, ficou determinado que deveriam ser desenvolvidas ações relativas a moradia estudantil, alimentação, transporte, assistência à saúde, inclusão digital, cultura, esporte, creche, apoio pedagógico e acesso, participação e aprendizagem de estudantes com deficiência, com transtornos globais do desenvolvimento e altas habilidades e superdotação, atribuindo-se a cada instituição determinar como serão desenvolvidas as ações e a forma como serão utilizados os recursos orçamentários. Assim, cabe a cada instituição adequá-lo à sua realidade, respeitando sempre as condições previstas no Decreto que o criou.

\subsection{Vulnerabilidade}

A vulnerabilidade social abarca pessoas que, de alguma forma, estão expostas à exclusão social, de forma que, quando se fala em vulnerabilidade, geralmente há referência à pobreza, mas esse termo não compreende apenas a pobreza. Sob esse enfoque, estão incluídas em vulnerabilidade social as pessoas que, geralmente, moram na rua e/ou dependem de favores e da ajuda de outras pessoas, ou mesmo quando não têm suas necessidades básicas satisfeitas, a 
exemplo daqueles que estão abaixo da linha de pobreza, a qual é definida pelo Banco Mundial, em seu Relatório de Desenvolvimento Mundial de 1990, como sendo aquelas que vivem com menos de 1 dólar por dia.

Para complementar a ideia, convém citar a definição de vulnerabilidade proposta por Katzman (2005, p. 4):

Vulnerabilidad no es exactamente lo mismo que pobreza se bien la incluye. Esta última hace referencia a una situación de carencia efectiva y actual mientras que la vulnerabilidad trasciende esta condición proyectando a futuro la posibilidad de padecería a partir de ciertas debilidades, que se constatan en el presente.

A vulnerabilidade caracteriza-se por ser um campo complexo que é constituído por diversas concepções, que, a depender do caso, volta-se para o enfoque econômico, de saúde, de educação etc. Em um estudo realizado pela Organização das Nações Unidas para a Educação, a Ciência e a Cultura (UNESCO) e o Banco Interamericano de Desenvolvimento (BID), observa-se, entre outras informações, o fato de que as políticas sociais não alcançaram as raízes do fenômeno da vulnerabilidade social por se embasarem, basicamente, em indicadores de renda ou carência como sendo balizadores da insatisfação das necessidades básicas.

Apesar do uso histórico do termo vulnerabilidade em diversos estudos sociais, as aproximações analíticas à vulnerabilidade social datam apenas dos últimos anos, período em que se levou a cabo maior reflexão a respeito das limitações dos estudos sobre a pobreza e sobre os escassos resultados das políticas associadas a eles na América Latina. Tais enfoques da pobreza - apesar de servirem à identificação dos setores mais desprovidos da população a serem atendidos pelas políticas sociais - não deram conta das complexas raízes desse fenômeno, já que se baseavam apenas no uso de indicadores de renda ou carências que delimitam a insatisfação de necessidades básicas (ABRAMOVAY, 2002, p. 23).

A supracitada autora, ao colocar que são recentes os estudos sobre a vulnerabilidade, destaca que as reflexões davam mais ênfase para os aspectos relacionados à pobreza, e esse fator serviu para identificar os setores mais pobres da população, pois os estudos eram fundamentados, por exemplo, em indicadores de renda e necessidades básicas.

Os primeiros trabalhos ancorados na perspectiva da vulnerabilidade social foram desenvolvidos, motivados pela preocupação de abordar, de forma mais integral e completa, não somente o fenômeno da pobreza, mas também as diversas modalidades de desvantagem social. Tais obras se destinaram a observar os riscos de mobilidade social descendente e as configurações vulneráveis que não se restringiam àqueles situados abaixo da linha de pobreza, mas a toda população em geral. Dessa maneira, partiam do reconhecimento do fenômeno do bem-estar social de uma maneira dinâmica, bem como das múltiplas causas e dimensões associadas a esse processo (ABRAMOVAY, 2002, p. 24).

A autora, ainda, complementa a ideia de insatisfação das necessidades básicas, ao mostrar uma perspectiva de trabalhos desenvolvidos com a preocupação de abordar a vulnerabilidade não apenas como um fenômeno ligado à pobreza, mas também com uma visão mais ampla, que enquadra diversas modalidades de desvantagens sociais.

Pode-se considerar que uma pessoa está em vulnerabilidade socioeconômica quando, temporariamente ou por longo espaço de tempo, apresente sinais de desnutrição, esteja em condições precárias de moradia e/ou de saneamento, não possua família ou emprego. Estes são alguns fatores que compõem o risco social, ou seja, o indivíduo é um cidadão, mas não consegue ter os mesmos direitos e deveres que os demais, e é excluído e impossibilitado de partilhar dos bens e recursos oferecidos pela sociedade, o que acarreta o seu abandono e, na maioria das vezes, a sua expulsão dos espaços da sociedade. 
Dificuldades econômicas costumam estar associadas a fatores como desemprego, problemas habitacionais e de saneamento, baixa escolaridade, famílias com maior número de crianças ou dependentes (como idosos e doentes), dificuldades de acesso a recursos comunitários, presença de situações de violência. Fatores como esses expõem as famílias à vulnerabilidade social e de saúde física e mental. (SCHLITHLER et al., 2010, p. 56).

A vulnerabilidade socioeconômica traz a ideia de impossibilidade de uma pessoa ou de um grupo de pessoas de aproveitar as oportunidades para a obtenção de uma melhora pessoal ou social. Dessa maneira, para melhor definir o termo, tem-se que, constantemente, implementar políticas sociais com o intuito de concretizar uma perspectiva preventiva e protetiva para afastar ou minimizar impactos causados às pessoas que estão em situações-limites.

O Brasil, por obrigação legal, tem que assegurar direitos e promover a educação. É nessa linha de raciocínio que se introduzem as políticas públicas que visam garantir o direito de igualdade e de oportunidades a todos os cidadãos. Neste panorama, surgiu o Programa Nacional de Assistência Estudantil (PNAES), com a finalidade de ampliar as condições de permanência dos discentes na educação, diminuindo a evasão, aumentando o aproveitamento escolar e, dessa maneira, contribuindo para a conclusão do curso pretendido.

O Distrito Federal apresenta, em seu território, disparidades socioeconômicas. Em sua pequena extensão, a Capital Federal possui áreas mais privilegiadas do que outras, em razão de políticas de investimento e infraestrutura. Considerando-se que este estudo tem a finalidade estudar os discentes matriculados no Campus Taguatinga e que eles, por sua vez, encontram-se localizados em alguma das regiões administrativas, convém trazer, para complementar o entendimento, o Índice de Vulnerabilidade Social das Regiões Administrativas do DF, conforme pesquisa realizada pelo DIEESE (Departamento Intersindical de Estatística e Estudos Socioeconômicos). Para identificar os Índices de Vulnerabilidade Social existentes no Distrito Federal, o DIEESE utiliza as condições socioeconômicas por ele preestabelecidas.

Tabela 1 - Índice de Vulnerabilidade Social do Distrito Federal (2010)

\begin{tabular}{l|c|l|c}
\hline Região Administrativa & $\begin{array}{c}\text { Índice de } \\
\text { vulnerabilidade social }\end{array}$ & Região Administrativa & $\begin{array}{c}\text { Índice de } \\
\text { vulnerabilidade social }\end{array}$ \\
\hline Brasília & 43,3 & Recanto das Emas & 54,4 \\
\hline Brazlândia & 48,6 & Riacho Fundo I & 45,4 \\
\hline Candangolândia & 36,4 & Riacho Fundo II & 44,3 \\
\hline Ceilândia & 55,1 & Samambaia & 51,4 \\
\hline Estrutural & 60,1 & Santa Maria & 48,6 \\
\hline Gama & 48,3 & São Sebastião & 52,6 \\
\hline Guará & 44,2 & Sobradinho I & 46,8 \\
\hline Itapoã & 62,0 & Sobradinho II & 48,2 \\
\hline Núcleo Bandeirante & 41,6 & Taguatinga & 42,5 \\
\hline Paranoá & 52,6 & Varjão & 64,7 \\
\hline Planaltina & 53,8 & Vicente Pires & 29,6 \\
\hline
\end{tabular}

Fonte: Recuperado de DIEESE. Pesquisa Socioeconômica em Territórios de Vulnerabilidade Social no Distrito Federal

Tendo em vista que o Campus Taguatinga encontra-se fixado na Região Administrativa de Taguatinga, este, por sua vez, conforme a tabela de Índice de Vulnerabilidade do DIEESE, situa-se em uma comunidade com o percentil de 42,5.

No que se refere ao programa de assistência estudantil, a condição socioeconômica do aluno é extremamente importante, pois serve de balizador para caracterizar o discente que se encontra vulnerável no tocante a recursos financeiros.

Desse modo, o objetivo de se avaliar o perfil do discente consiste em classificá-lo de acordo com indicadores socioeconômicos, tais como renda familiar per capita, bens patrimoniais, status ocupacional, tipo de residência da família, situação de residência do estudante e procedência escolar do estudante. 


\subsection{Política de Assistência Estudantil - PAE}

O Decreto no 7.234/2010, que estabelece o Programa Nacional de Assistência Estudantil (PNAES), traz, em seu art. 1ำ, que o Programa será executado no âmbito do Ministério da Educação (MEC), com a finalidade de ampliar as condições de permanência dos jovens na educação superior pública federal. $\mathrm{O}$ artigo 40 incluiu, no Programa, os Institutos Federais de Educação, considerando-se suas especificidades e áreas estratégicas de ensino, visando atender ao seu corpo discente. Dessa forma, a assistência estudantil, no âmbito dos Institutos Federais, incluiu todos os seus alunos, tanto os do ensino técnico quanto os do ensino superior.

Art. 4으 As ações de assistência estudantil serão executadas por instituições federais de ensino superior, abrangendo os Institutos Federais de Educação, Ciência e Tecnologia, considerando suas especificidades, as áreas estratégicas de ensino, pesquisa e extensão e aquelas que atendam às necessidades identificadas por seu corpo discente (Decreto no 7.234, de 19 de julho de 2010).

Com base no referido Decreto, o Instituto Federal de Brasília optou por criar sua política própria. Visando melhorias na execução do programa, por meio da Resolução no 14/2014/CS-IFB, o IFB regulamentou, em maio de 2014, sua Política de Assistência Estudantil (PAE), vigente até os dias atuais, a qual regulamentou os programas de assistência ao estudante, cujo objetivo está expresso no seu artigo 10:

Art. 10 A Política de Assistência Estudantil do Instituto Federal de Educação, Ciência e Tecnologia de Brasília - IFB -é um conjunto de princípios e diretrizes que norteia a implantação de ações que promovam o acesso, a permanência e o êxito dos estudantes, na perspectiva de inclusão social, produção de conhecimento, melhoria do desempenho escolar e da qualidade de vida. (Resolução no 14/2014/CS-IFB)

A PAE prevê as diretrizes e os princípios que norteiam a implantação de ações que visam à permanência dos alunos e traz a composição das equipes de trabalho e as suas responsabilidades. Em seu artigo 18, a PAE instituiu três grupos de programas: os programas universais, os de promoção à permanência e os de incentivo ao desenvolvimento acadêmico. Esses últimos visam apoiar os estudantes de forma a favorecer a sua permanência e o seu êxito acadêmico.

A PAE/IFB é coordenada pela Pró-Reitoria de Ensino (PREN), em parceria com os campi, devendo outras coordenações, tais como a Coordenação de Assistência Estudantil e Inclusão Social dos Campi, desenvolver, junto com outros setores, ações e programas que tenham natureza, por exemplo, de cunho social, cultural, científico etc.

Cada programa tem a forma de ingresso. O de promoção à permanência, por exemplo, define que, para participar, o discente terá que preencher os requisitos de participação, que serão expressos em edital de ampla concorrência na instituição. Os editais são publicados por Campi, e uma vez a cada semestre. Para ter acesso aos programas de promoção à permanência, exceto o auxílio integrado, os alunos passarão por estudo socioeconômico, a ser realizado pela Equipe de Serviço Social do IFB, e podem, ainda, passar por entrevistas e visitas domiciliares.

O IFB prestará assistência ao discente, incluído no programa de promoção à permanência, sob a forma de repasse financeiro, por meio de ordem de pagamento, e os recursos relacionados 
à assistência serão originários de sua matriz orçamentária do MEC, em consonância com o Decreto no $7.234 / 2010$.

Depois de realizado o estudo, a classificação dos candidatos dar-se-á mediante pontuação e parecer do assistente social. No que se refere ao auxílio-permanência, os estudantes também serão classificados no Grupo 1 ou no Grupo 2.

A apreciação da Equipe de Serviço Social dar-se-á pela análise dos dados apresentados, tais como renda familiar per capita, número de habitantes na residência, tipo de moradia (cedida, alugada, financiada), local da moradia, número e idade dos filhos, portador de doença crônica, portador de deficiência ou responsável por portador de deficiência, cor, etnia, mulher chefe de família, situação de trabalho do discente ou do responsável mantenedor (empregado ou desempregado) e, por último, membro de família beneficiária da seguridade social (exemplo: beneficiários do Programa Bolsa Família e/ou que possuem familiar que recebe Benefício de Prestação Continuada).

No âmbito do IFB, a política de assistência estudantil opera por meio dos seguintes programas: Programas Universais, Programas de Promoção à Permanência e Programas de Incentivo ao Desenvolvimento Acadêmico.

Para atender aos discentes que se encontram em vulnerabilidade, com necessidade de receber auxílio financeiro, esses são contemplados com os Programas de Promoção à Permanência, alçando mão dos programas abaixo listados:

a) Programa Auxílio Permanência - objetiva minimizar as desigualdades sociais dos estudantes em vulnerabilidade socioeconômica, com o intuito de contribuir com sua permanência e com a conclusão do curso;

b) Programa Apoio ao Proeja - objetiva contribuir para a permanência e a manutenção do estudante, visando à melhoria do seu desempenho acadêmico, por meio da concessão de auxílio financeiro;

c) Programa Auxílio Moradia - é um auxílio pecuniário, que objetiva custear parte dos gastos com aluguel em regiões próximas aos campi;

d) Programa de Residência Estudantil - disponibilização de residência estudantil para os estudantes em vulnerabilidade socioeconômica, atendendo, preferencialmente, aos estudantes que residam fora do Distrito Federal e que estejam matriculados em cursos no Campus Planaltina;

e) Programa Auxílio Criança - o auxílio criança tem por finalidade contribuir para a permanência e a diminuição da evasão dos estudantes pais/mães matriculados nos cursos do IFB;

f) Programa Apoio ao Integrado - objetiva contribuir, com auxílio financeiro, para garantir o direito à alimentação saudável no horário das aulas, visando à permanência dos estudantes matriculados nos cursos técnicos integrado ao ensino médio.

O processo de seleção é feito por meio de edital, podendo dele participar todos os estudantes matriculados no IFB, e suas cláusulas são norteadoras para a escolha dos discentes que se encontram em vulnerabilidade socioeconômica. Depois de realizadas todas as etapas da seleção, considerando-se o aspecto da vulnerabilidade socioeconômica dos discentes, eles são classificados, no caso do auxílio permanência, em grupos: 
- Grupo 1 (G1): situação de alta vulnerabilidade socioeconômica. O discente apresenta grande dificuldade em satisfazer suas necessidades básicas (alimentação, transporte, material escolar), fato que pode resultar em abandono do curso por insuficiência de recurso financeiro;

- Grupo 2 (G2): situação de média vulnerabilidade socioeconômica. O discente encontra-se em suficiência parcial para a manutenção dos estudos.

A divisão nos mencionados grupos tem como objetivo privilegiar os discentes que estão em maior vulnerabilidade, com a finalidade de evitar a evasão ou a diminuição no aprendizado. Desse modo, de acordo com a Portaria Normativa no 005, de 10 de agosto de 2014, os valores da bolsa do Auxílio Permanência, para o G1, são de $\mathrm{R} \$ 250,00$ (duzentos e cinquenta reais) e, para o $\mathrm{G} 2$, de $\mathrm{R} \$ 150,00$ (cento e cinquenta reais).

Esses valores são repassados aos estudantes uma vez por mês, por meio de ordem bancária, após aferida a frequência dos discentes, atividade realizada em conjunto pelos docentes, pelo serviço de registro acadêmico e por assistente social.

\section{PERCURSO METODOLÓGOCO}

Para o desenvolvimento deste artigo, foi utilizado o estudo de caso exploratório descritivo de natureza qualitativa, conforme propôs Yin (2010), Gil (2010) e Silvestre (2007). Dessa forma, coube a este trabalho realizar um estudo com a finalidade de descrever o perfil dos discentes do Campus Taguatinga, unidade descentralizada do IFB, contemplados no Programa de Promoção à Permanência, já que a Política de Assistência Estudantil (PAE) tem como um de seus objetivos minimizar as desigualdades sociais dos estudantes em vulnerabilidade socioeconômica, de forma a contribuir com a permanência deles no Campus e com a conclusão do curso.

Em virtude da amplitude e da abrangência da PAE, o campo de estudo desta pesquisa limitar-se-á à análise do Programa de Promoção à Permanência do IFB, por meio da realização de uma prévia dos dados dos discentes contemplados pelo Programa, coletados no Campus Taguatinga.

A amostra deste estudo, Campus Taguatinga, é uma unidade do IFB, instituição de ensino que pertence à Rede Federal de Educação Profissional, Científica e Tecnológica, a qual foi instituída por meio da Lei no 11.892, de 29 de dezembro de 2008, quando o governo federal brasileiro criou a rede de Institutos Federais.

O Campus Taguatinga do IFB oferece formação nas áreas de Comércio, Vestuário, Eletromecânica, Informática e Licenciatura em Física, cuja vocação foi definida por meio de consultas à sociedade, com base em dados socioeconômicos da região. São oferecidos cursos técnicos, cursos de formação inicial e continuada (FIC), projetos de extensão e cursos de idiomas, além do projeto Mulheres Mil.

Por se tratar de um Programa pertencente à esfera federal, foram analisadas portarias internas e a Resolução no 14/2014/CS-IFB do Órgão Colegiado, para, assim, caracterizar-se as ações que estão sendo desenvolvidas no Programa de Promoção à Permanência no Campus, de acordo com a PAE e o PNAES.

Para alcançar os objetivos propostos, foi necessário, também, utilizar documentos internos do IFB, como o Estatuto do IFB, as Resoluções do Conselho que tratam da criação dos cursos, a Política de Assistência Estudantil, as portarias de criação dos campi e os dados dos discentes contemplados no programa, conforme os dados expostos no Quadro 1. 


\section{Quadro 1 - Relação de Portarias de criação dos Campi}

\begin{tabular}{|l|l|}
\hline CAMPI & PORTARIAS DE CRIAÇÃO \\
\hline $\begin{array}{l}\text { Planaltina, Brasília, Gama, Samambaia e } \\
\text { Taguatinga }\end{array}$ & $4 / 2009$ \\
\hline $\begin{array}{l}\text { Taguatinga Centro, São Sebastião e Riacho } \\
\text { Fundo }\end{array}$ & $330 / 2013$ \\
\hline Estrutural e Ceilândia & $993 / 2013$ \\
\hline
\end{tabular}

Fonte: Dados da pesquisa, 2015.

Para efeito dessa análise prévia, foram utilizados, como amostra, dados de 109 discentes contemplados no Programa de Promoção à Permanência, no primeiro semestre de 2014, no Campus Taguatinga do IFB. Os dados foram analisados por meio da estatística descritiva nominal a partir de elementos extraídos da análise dos formulários preenchidos pelos alunos contemplados no programa, sendo que os referidos formulários foram disponibilizados para este estudo pela Pró-Reitoria de ensino do IFB.

Os dados extraídos foram analisados com base em categorias de gênero, nível de escolaridade, faixa etária, tipo de residência, forma de locomoção para a escola, local onde o discente cursou o ensino fundamental e o ensino médio, estatuto ocupacional do discente e, por fim, a renda per capita das famílias dos estudantes, para fins de identificação do perfil do discente contemplado pelo programa.

\section{RESULTADOS E DISCUSSÕES}

O IFB foi contemplado no PNAES, como pode ser observado no artigo 40 do Decreto no 7.234/2010, motivo pelo qual construiu sua própria Política de Assistência Estudantil (PAE), como meio de garantir o acesso e a permanência do discente no curso em que está matriculado.

O Campus Taguatinga, objeto deste estudo, integra o IFB, uma instituição de ensino pertencente à Rede Federal de Educação Profissional, Científica e Tecnológica, o qual, atualmente, é composto por 10 campi, localizados nas Regiões Administrativas do Distrito Federal, como se observa na Figura 1, a seguir.

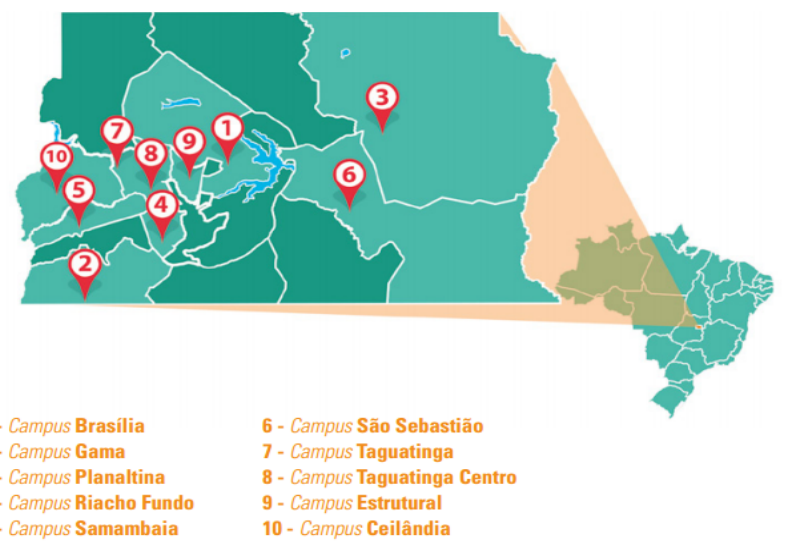

Figura 1. Distribuição dos Campi do Instituto Federal de Brasília.

Nota. Fonte: IFB, Manual do Estudante, 2015 
Este artigo traz os resultados da pesquisa qualitativa acerca do perfil dos discentes do Campus Taguatinga, no ano letivo de 2014, que se encontravam em situação de vulnerabilidade socioeconômica e que foram contemplados pelo Programa de Promoção à Permanência.

Considerando-se que há, no Campus Taguatinga, a aplicação da Política de Assistência Estudantil do IFB, para restringir a análise, este estudo limitou-se ao Programa de Promoção à Permanência, voltado aos discentes que se encontram em vulnerabilidade social, tanto para aqueles que estão no nível técnico, como para os de nível superior.

Dessa forma, após a publicação do Edital de seleção para o Programa de Promoção à Permanência, no Campus Taguatinga, no primeiro e no segundo semestre de 2014, 172 (cento e setenta e dois) discentes foram contemplados no Programa de Promoção à Permanência. No que se refere à categoria gênero, $40,69 \%$ dos discentes são do gênero feminino e 59,30\% são do gênero masculino.

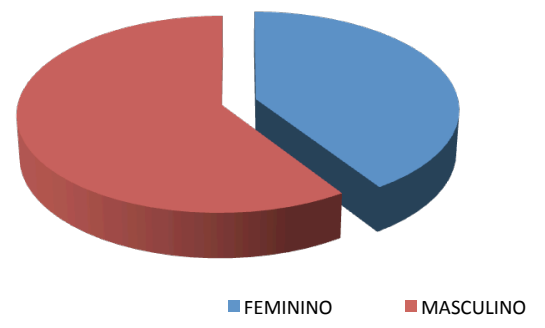

Gráfico 1. Gênero dos discentes contemplados, 2015.

Nota. Fonte: Levantamento dos dados secundários elaborado nesta pesquisa.

Por meio do levantamento exposto no Gráfico 1, afere-se que a maioria dos contemplados no programa é do gênero masculino, resultado que vem ao encontro do eixo tecnológico de produção industrial, de controle e processos industriais e de informação e comunicação, que são desenvolvidos no Campus, por meio de cursos como técnico em eletromecânica, técnico em suporte de manutenção de redes, aprendiz de mecânica e ciência da computação.

Em vista da peculiaridade do IFB, no qual está inserido o Campus Taguatinga, no que se refere à oferta de cursos profissionalizantes, cerca de $81 \%$ dos discentes contemplados estavam matriculados em cursos técnicos, ao passo que $19 \%$ estavam matriculados em curso de nível superior, conforme o Gráfico 2.

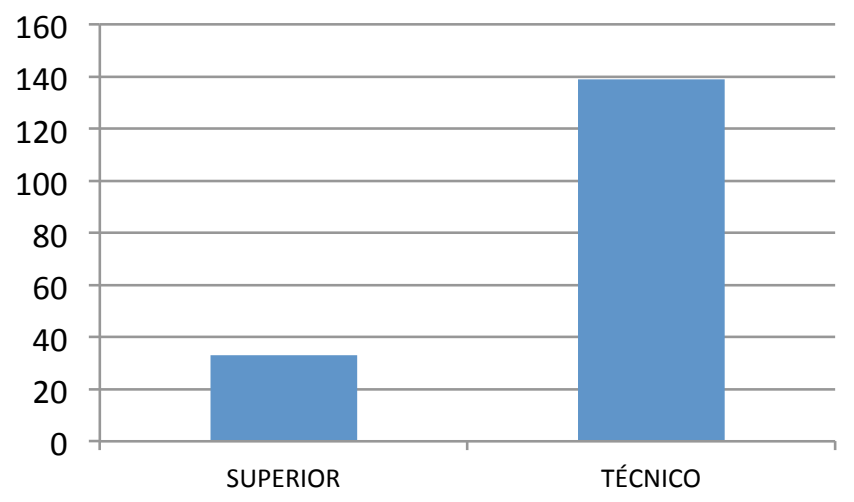

Gráfico 2. Distribuição dos discentes contemplados por nível de escolaridade, 2015.

Nota. Fonte: Levantamento dos dados secundários elaborado nesta pesquisa. 
Os dados apresentados no Gráfico 2 retratam que a maioria dos estudantes cursava algum curso técnico, pois, como o IFB encontra-se em fase de implantação, estavam em pleno funcionamento, no Campus Taguatinga, dois cursos de nível superior, que são o Bacharelado em Ciências da Computação e a Licenciatura em Computação, em detrimento dos demais cursos de nível técnico, quais sejam: Técnico em Eletromecânica, Técnico em Suporte e Manutenção em Informática, Técnico em Vestuário e Técnico em Artesanato.

A idade dos estudantes contemplados no Programa de Promoção à Permanência foi classificada em três faixas: 2,32\% dos discentes estão na faixa de 14 a 17 anos de idade, 47,1\% encontram-se na faixa de 18 a 29 anos de idade e 50,58\% estão na faixa de 30 a 60 anos de idade. Dessa forma, observa-se que os discentes contemplados no Programa estão concentrados na faixa etária compreendida entre 18 e 60 anos de idade.

A concentração dos estudantes na faixa de idade superior a 18 anos de idade encontra-se ancorada na oferta de cursos no Campus, que prevalece na modalidade técnico subsequente, oferecida aos estudantes que já concluíram o ensino médio e que estão em busca de um curso profissionalizante.

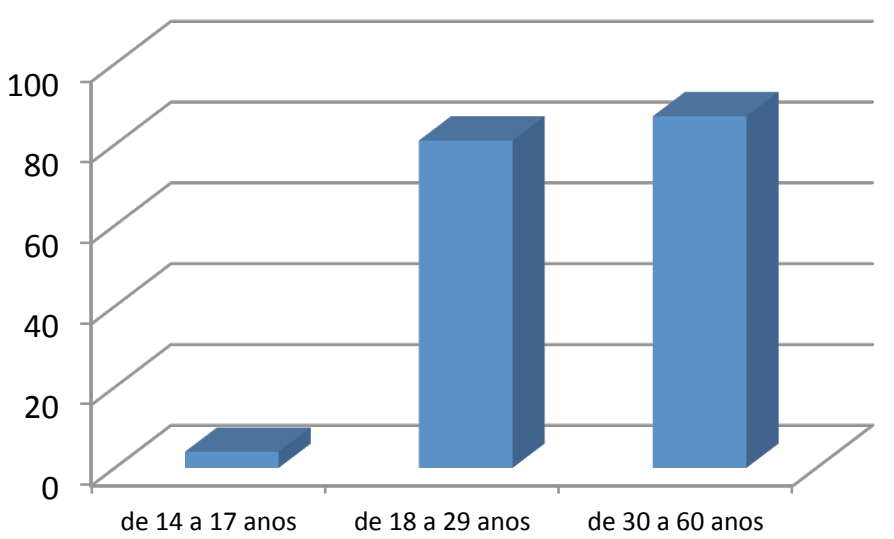

Gráfico 3. Distribuição dos discentes contemplados por faixa etária, 2015 Nota. Fonte: Levantamento dos dados secundários elaborado nesta pesquisa.

Ao se considerar que o Campus Taguatinga está localizado em uma área urbana da Região Administrativa de Taguatinga, 92,4\% dos discentes contemplados residem em área urbana, e apenas $7,6 \%$ são da área rural. Para se locomoverem até a escola, 77,9\% dos estudantes utilizam o transporte público, em detrimento de outros tipos de transportes. Isso ocorre porque a maioria da clientela dos cursos, os quais são criados a partir de consulta pública, seja das imediações, o que corrobora o fato de os estudantes utilizarem o transporte público para se deslocarem de casa ou do trabalho para a escola.

Entre os contemplados, $90,7 \%$ cursou o ensino fundamental na rede pública e $87,2 \%$ cursou o ensino médio na mesma rede, o que demostra que a maioria dos discentes contemplados pelo Programa estudou na rede pública ou por opção ou por necessidade, cabendo a uma pesquisa específica determinar os motivos pelos quais os estudantes recorreram à rede pública para estudar.

O Programa de Promoção à Permanência visa privilegiar os discentes que estão em maior grau de vulnerabilidade socioeconômica, como forma de evitar a evasão ou a diminuição no aprendizado. Assim, a análise realizada pelos assistentes sociais para selecionar os discentes em situação de vulnerabilidade permeia os dados referentes às condições socioeconômicas de cada discente, pontuando-o e categorizando-o em conformidade com a renda familiar per capita, os 
bens patrimoniais, o estatuto ocupacional, o tipo de residência da família, a situação de residência e a procedência escolar do estudante.

Sob esse enfoque, registre-se que $64,5 \%$ dos discentes contemplados pelo Programa estavam desempregados ou nunca trabalharam, ao passo que $22,1 \%$ encontram-se ocupando uma vaga no mercado de trabalho. Os demais discentes $(13,4 \%)$ encontram-se aposentados ou são trabalhadores autônomos. Levando em conta que a maioria dos discentes cursou o nível médio e está na faixa etária superior a 18 anos de idade, denota-se que há um percentual elevado de discentes fora do mercado de trabalho e em busca de capacitação, e sendo beneficiado em um Programa que auxilia na permanência no curso.

Considerando-se que o valor de referência do salário mínimo é o ano de 2014, e que o salário mínimo era de $\mathrm{R} \$ \mathbf{7 2 4 , 0 0}$ à época, no que se refere à renda per capita, cabe complementar que, dos 172 contemplados, 22,1\% estavam na faixa entre $R \$ 181,00$ e $R \$ 362,00$, $32,6 \%$ estavam inseridos em família cuja renda per capita estava compreendida entre $\mathrm{R} \$ 362,01$ e $R \$ 724,00$, e $23,2 \%$ estavam na faixa compreendida entre $R \$ 724,00$ e $R \$ 1.086,00$. Cerca de $22,1 \%$ dos estudantes restantes estavam distribuídos em outras faixas de renda, acima dos valores estabelecidos pelas regras do Programa.

Portanto, do total de 172 discentes contemplados no Programa de Promoção à Permanência, 54,7\% estavam inseridos em famílias cuja renda per capita concentrava-se na faixa entre $\mathrm{R} \$ 181,00$ e $\mathrm{R} \$ 724,00$. Esse fato corrobora as diretrizes do Programa de Promoção à Permanência, segundo as quais, para participar dele, os estudantes deveriam possuir renda per capita de até um salário mínimo e meio, ou seja, R\$1.086,00, em 2014.

Com base nos dados apresentados, o perfil do discente contemplado pelo Programa de Promoção à Permanência equivale à discentes do gênero masculino, com idade superior a 18 anos de idade, que residem em área urbana, a maioria dos quais estão desempregados, oriundos da rede pública de ensino e com renda per capita inferior ao valor de um salário mínimo e meio.

\section{CONCLUSÕES}

Este estudo buscou descrever a evolução do PNAES e da Política de Assistência Estudantil (PAE), no âmbito do Campus Taguatinga, unidade do Instituto Federal de Educação, Ciência e Tecnologia de Brasília (IFB), com o intuito de analisar o perfil socioeconômico dos discentes contemplados no Programa de Promoção à Permanência.

A partir dos resultados encontrados, concluiu-se que o Programa atende aos estudantes com o perfil estabelecido pelo Programa Nacional de Assistência Estudantil (PNAES), cujo objetivo é o de viabilizar a igualdade de oportunidades entre os alunos.

O desenvolvimento deste estudo permitiu ter uma visão clara a respeito do perfil dos discentes contemplados, pois, de acordo com a análise dos resultados, o Programa de Promoção à Permanência atendeu ao propósito para o qual foi instituído, uma vez que foram atendidos estudantes que se encontravam em situação de vulnerabilidade socioeconômica.

Os dados levantados demonstraram que o perfil do discente contemplado pelo Programa de Promoção à Permanência concentra-se em adultos com idade superior a 18 anos de idade, do gênero masculino, residentes em área urbana, provenientes da rede pública de ensino, com renda per capita inferior ao valor de um salário mínimo e meio, e que estavam, em sua maioria, fora do mercado de trabalho formal, mas em busca de capacitação. 
Portanto, considerando-se o perfil dos contemplados pelo programa, observa-se que o benefício ofertado equivale a um auxílio importante, que busca sanar as condições socioeconômicas desfavoráveis dos discentes e que, de fato, auxilia em sua permanência no curso e na conclusão desse.

Espera-se que o Programa de Promoção à Permanência continue a ser encarado com a seriedade que necessita, em virtude de sua importância para os discentes que estão em situação de vulnerabilidade socioeconômica e que têm, nesse Programa, a esperança de minimizar a desigualdade em relação aos colegas de classe e, por conseguinte, a oportunidade de concluir o curso, sem dele precisar desistir, bem como de melhorar o seu futuro.

\section{REFERÊNCIAS}

ABRAMOVAY, M.; CASTRO, M. G.; PINHEIRO, L. de C.; LIMA, F. de S.; \& MARTINELLI, C. da C. (2002). Juventude, violência e vulnerabilidade social na América Latina: desafios para políticas públicas. Brasília: UNESCO/BID.

ARAÚJO. F. S. de; BEZERRA, J. C. B. (2007, agosto). Tendências da política de assistência ao estudante no contexto da reforma universitária brasileira. III Jornada Internacional de Políticas Públicas. Universidade Federal do Maranhão. Recuperado em 2 julho, 2015, de http://www.joinpp.ufma.br/jornadas/joinpplll/html/Trabalhos/EixoTematicoA/cff899684c7e f149b573Fabr\%C3\%ADcia\%20Silva\%20de\%20Ara\%C3\%BAjo.pdf

Constituição da República Federativa do Brasil de 1988 (1988). Recuperado em 6 dezembro, 2014, de http://www.planalto.gov.br/ccivil_03/constituicao/constituicaocompilado.htm

Decreto no 7.234, de 19 de julho de 2010 (2010). Dispõe sobre o Programa Nacional de Assistência Estudantil - PNAES. Recuperado em 3 outubro, 2014, de http://www.planalto.gov.br/ccivil_03/_Ato2007-2010/2010/Decreto/D7234.htm

GIL, Antonio Carlos (2010). Como elaborar projetos de pesquisa. 5. ed. São Paulo: Atlas.

IFB [Instituto Federal de Educação, Ciência e Tecnologia de Brasília]. Estatuto do IFB. Recuperado em 3 outubro, 2014, de https://www.ifb.edu.br/attachments/007_201032010421150estatut o_ifb_aprovadao_e_enviado_ao_mec_agosto_2009.pdf

Resolução no 014/2014/CS-IFB (2014, maio). Aprova a Política de Assistência Estudantil (PAE), do Instituto Federal de Educação, Ciência e Tecnologia de Brasília. Recuperado em 3 outubro, 2014, de https://www.ifb.edu.br/attachments/article/6397/Resolu\%C3\%A7\%C3\%A 3o_014_Aprova\%20a\%20Pol\%C3\%ADtica\%20e\%20Assist\%C3\%AAncia\%20Estudantil\%20do\% 20IFBpdf.pdf

Lei no 9.394, de 20 de dezembro de 1996 (1996). Estabelece as diretrizes e bases da educação nacional. Recuperado em 3 outubro, 2014, de http://www.planalto.gov.br/ccivil_03/Leis/193 94.htm

Lei no 11.892, de 29 de dezembro de 2008 (2008). Institui a Rede Federal de Educação Profissional, Científica e Tecnológica, cria os Institutos Federais de Educação, Ciência e Tecnologia, e dá outras providências. Recuperado em 3 outubro, 2014, de http://www.planalto.gov.br/ccivil_03/_ato2007-2010/2008/lei/l11892.htm

MARCONI, M. de A.; LAKATOS, E. M. (2003). Fundamentos de metodologia científica. 5. ed. São Paulo: Atlas. 
Ministério da Educação, Brasil. (2007). O Plano de Desenvolvimento da Educação: razões, princípios e programas - PDE. Brasília, 2007. (Caderno de divulgação das razões, princípios e programas do PDE.)

(2007). Portaria Normativa no 39, de 12 de dezembro de 2007. Institui o Programa Nacional de Assistência Estudantil - PNAES. Recuperado em 3 outubro, 2014, de http://portal.mec.gov.br/arquivos/pdf/portaria_pnaes.pdf

REIS, A. S. dos. Breve história da legislação educacional no Brasil. Recuperado em 1 julho, 2015, de www.cefetsp.br/edu/eja/historia_legislacao_brasil.doc

SCHLITHLER, A. C. B.; CERON, M.; GONÇALVES, D. A. (s.d.). Famílias em situação de vulnerabilidade ou risco psicossocial (Módulo Psicossocial, pp. 45-69). Especialização em Saúde da Família. UNA-SUS/UNIFESP. Recuperado em 5 julho, 2015, de http://www.unasus.unifesp.br/biblioteca_virtual/esf/1/modulo_psicossocial/Unidade_18 .pdf.

SILVEIRA, M. M. da (2012). A assistência estudantil no Ensino Superior: uma análise sobre as políticas de permanência das universidades federais brasileiras. Dissertação de mestrado, Universidade Católica de Pelotas, Pelotas, RS, Brasil. Recuperado em 5 julho, 2015, de http://antares.ucpel.tche.br/mps/dissertacoes/Mestrado/2012/Disserta\%E7\%E3o_MiriamSil veira.pdf

SILVESTRE, A. L. Análise de dados e estatística descritiva. Lisboa: Escolar, 2007.

VASCONCELOS, N. B. (2010). Programa nacional de assistência estudantil: uma análise da evolução da assistência estudantil ao longo da história da Educação Superior no Brasil. Revista da Católica, 2(3), 399-411.

YIN, R. K. (2010) Estudo de caso: planejamento e métodos (4a ed.). (D. Grassi, Trad.). Porto Alegre: Bookman. (Obra original publicada em 1984). 